\title{
A Study on Natural Fracture Characterization for Well Trajectory Design and Production Improvement: A Case Study from A Tight Gas Reservoir, Australia
}

\author{
Azadeh Aghajanpour, Roohullah Qalandari, and Raoof Gholami Mian Poshteh
}

\begin{abstract}
Multiple deformation over geologic time leads to generation of natural fractures. In naturally fractured reservoirs (NFRs), there are sets of fractures favourably oriented to fail in shear under the present-day stress field. These fractures which are critically stressed or at the threshold of being critically stressed are more likely to create good fluid conduit and to be the producing fractures in the reservoir. Conversely, non-critically stressed fractures, despite of their extensive population, do not contribute much to the reservoir permeability. Thus, identification of the critically stressed fractures, their distribution and orientations, is imperative to optimize different stages of wellbore construction ranging from wellbore trajectory planning and placement, to stimulation strategy.

In this study, a tight sandstone reservoir was brought as a case study to indicate how production optimization can be achieved by a careful analysis of fractures. To do this, a comprehensive analysis was done on Formation Micro Scanner (FMS) $\log$ to identify the direction of principal stresses and natural fractures. This was followed by a thorough geomechanical model associated with coulomb failure function (CFF) to identify critically stressed natural fractures. Consequently, an optimized wellbore orientation was proposed to have the best production from the tight reservoir. In addition, the feasibility of underbalanced drilling performance due to minimizing formation damage was examined. A sensitivity analysis was also performed at the end to analyse the mud pressure reqired for hydraulic fracture propagation in order to effectively enhance reservoir permeability regarding various wellbore deviation and azimuth chosen for the wellbore.
\end{abstract}

Index Terms - Critically stressed natural fractures, wellbore trajectory, hydraulic fracturing.

\section{INTRODUCTION}

Production from extremely low permeability reservoirs such as tight sands has come into consideration because of their enhanced economic benefits [1], [2]. However, characterization of existing fractures is a crucial part of achieving an optimum production from such reserves as they have large impacts on the production performance analysis.

There is also an intense interaction between fractures in such reservoirs, which must not be neglected during drilling and

production. Thus, Characterization of the individual natural

Manuscript received February 8, 2018; revised May 5, 2018.

Azadeh Aghajanpour is with the Amirkabir University of Technology, Tehran, Iran (e-mail: azadehaghajanpour@gmail.com).

Roohullah Qalandari and Raoof Gholami are with Curtin University Malaysia, Miri, Sarawak, Malaysia (email: roohullahdanish@gmail.com raoof.gholami@curtin.edu.my). and tensile fractures is extremely important for all stages of well completion ranging from well placement and wellbore trajectory planning to hydraulic fracture stimulation procedure [1]-[3]

It is known that fractures which are critically stressed or at the threshold of being critically stressed under the present-day stress state, are likely to create good fluid conduit [4], [5]. In fact, they tend to act as the producing fractures under shear deformation. In order to optimize productivity, under these circumstances, wellbore trajectory must be designed such that majority of critically stressed fractures can be intersected largely by the well during drilling [6], [7]. Thus, determination of fracture orientation would play a key role in achieving a good production at later stages [2]-[11]

The aim of this paper is to provide a workflow through which a systematic fracture characterization can be done for a safer drilling and better production. A tight sandstone reservoir with multi-oriented natural fractures were used as part of this study to show the application of the method proposed. A comprehensive geomechanical model for one of the vertical exploration wells, known as WR, was built to determine the dominant stress regime in the field and magnitude of stresses. The direction of maximum horizontal stress was determined using oriented Calliper log and tensile fracture observed in the FMS log. The natural fractures were then analysed for their dip, azimuth, and distribution. This was followed by resolving shear and normal stresses on the fracture and fault planes to identify the critically stressed fractures. Ultimately, an optimum wellbore trajectory was proposed for intersecting the majority of critically stressed fractures during drilling. The feasibility of underbalanced drilling in sidetracks drilled at optimal well trajectories that intersected the maximum number of these fractures was also examined to mitigate the wellbore instability and reservoir formation damage. Eventually, required mud pressure for initiating the hydraulic fracture and its propagation was calculated. It could be used to enhance fracture reservoir permeability in the context of connecting natural fractures by these hydraulic fractures.

\section{Structural CHARACTERIZATION AND STRESS DIRECTION}

The first step of fracture characterization consists of identification of fractures and faults, as well as determination of stress direction from geomechanical features. The data set that might be used for such characterization includes borehole image logs such as FMI, EMI and FMS, core description related reports, Calliper 
logs, cross-dipole sonic logs, etc [8]-[10]. For the purpose of this study, digital Formation Micro scanner (FMS) data was used to analyse the drilling-induced fractures, borehole breakout and natural fractures. The results obtained were compared with 4-armed Calliper log data in well WR for further calibration.

It is known that drilling-induced tensile fractures are induced when the circumferential hoop stress becomes low and reaches the tensile strength of rocks. The propagation direction of these fractures, is however, in the direction of maximum principal stress in the wellbore [10]-[12]. On the contrary, borehole breakouts are observed when the maximum hoop stress becomes larger than the compressive strength of rocks. Its direction, however, would be along with the azimuth of minimum principal stress in the wellbore [13]. It should be noticed that the location, magnitude and orientation of the borehole failures are functions of wellbore orientation, dominant in-situ stress field and rock strength. Since the studied well, Well WR, is a vertical well, the direction of maximum horizontal stress corresponds to the direction of wellbore tensile failures. This direction can be inferred from the borehole breakouts, interpretation and analysis of FMS data. Herein, the FMS data at the measured depth of 3690- 3900 is shown as an example in Fig. 1. Fig. 2 illustrates the results of the wellbore failure analysis in the well WR.

The plots shown in Fig. 2 (a) indicate the orientation and width of wellbore breakouts (blue dots and bars) as a function of depth. Hole azimuth is shown by the red line on a scale of $0-360^{\circ}$. A histogram of the breakout orientation and breakout width was also shown in Fig. 2 (b) and (c). A rose diagram illustrates a consistent N-S breakout orientation in the well. The average maximum horizontal stress orientation inferred from the wellbore breakouts captured by the FMS $\log$ seems to be $85^{\circ} \mathrm{N} \pm 9^{\circ}$ (Fig. 2 (d)) which is consistent with the what was observed in the 4armed caliper data analysis. The results of this analysis indicated an approximately east-west maximum horizontal stress orientation for the studied field. The next step is to develop a geomechanical model for the well and estimate the magnitude of principal stress.

\section{GEOMECHANICAL MODELING}

A geomechanical model is built by integration of wireline logs with drilling events, core data and in-situ measurements. The Integration of these data constrains the geomechanical model and improve the estimation of in situ stresses and mechanical properties [9], [12]-[14]. Knowledge of rock strength is also essential for an accurate estimation of in situ stress during geomechanical modelling. Thus, a continuous profile of rock strength (UCS) was estimated using dipole sonic log data and empirical relationships, which was calibrated against laboratory measurements. In fact, (1) and (2) were used for the estimation of UCS in sandstone and shaly intervals, respectively [2], [3], [9]:

$$
\begin{gathered}
U C S=185,165 \times \exp (-0.037 \Delta t) \\
U C S=1.6 \times E^{0.71}
\end{gathered}
$$

where UCS is in psi, $\Delta t$ is sonic wave travel time in $\mu s / f t$, and $E$ is dynamic Young's modulus in psi, calculated from density, shear and compressional sonic logs. Pore pressure was another parameter required for estimation of in-situ stress which can be obtained using Eaton's method [14], [15] calibrated by MDT data. The results achieved from this calculation indicated a pore pressure gradient of $1.04 \mathrm{SG}$ in the well.

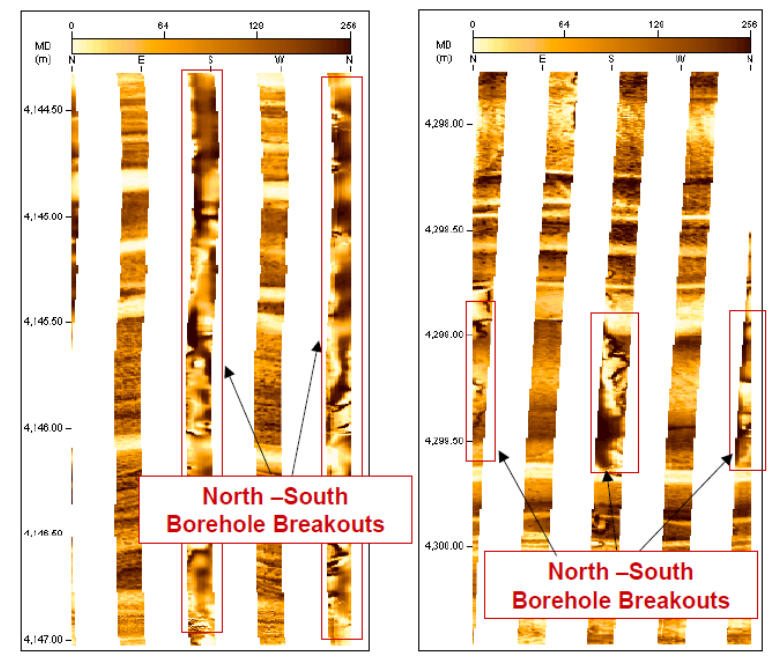

Fig. 1. Breakouts in micro-resistivity (FMS) image data from well WR. Magenta rectangles indicate the breakouts recorded in the resistivity image.

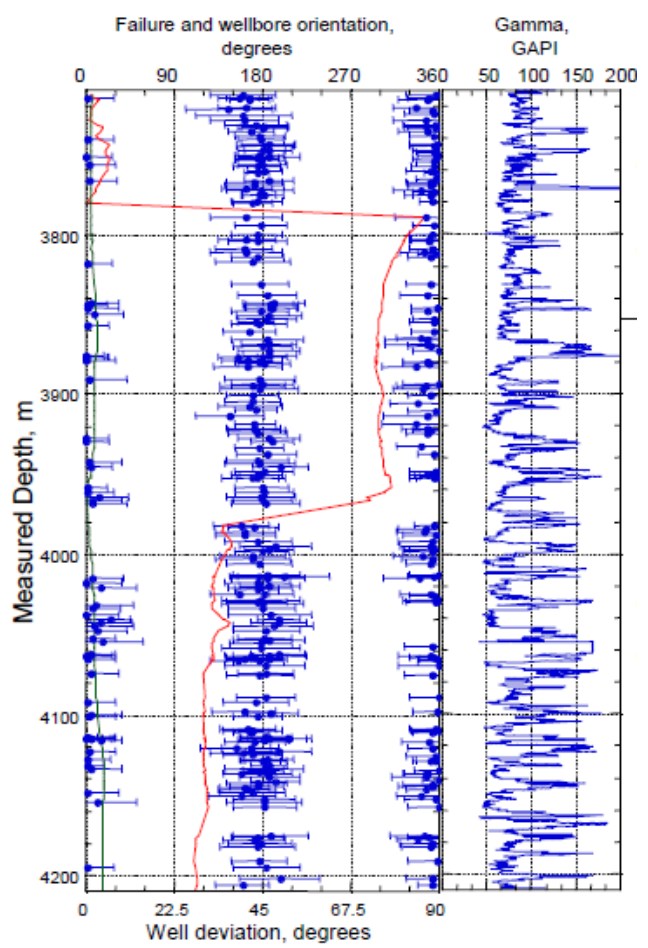

(a)

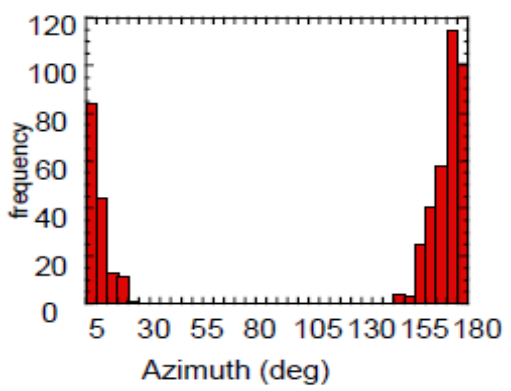

(b) 


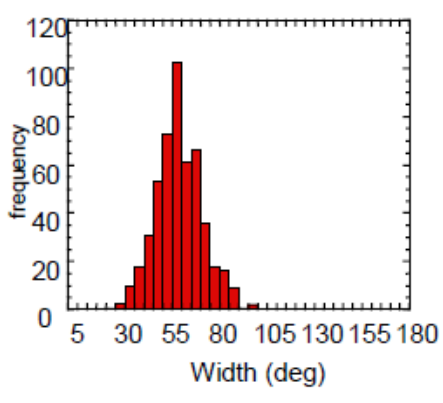

(c)

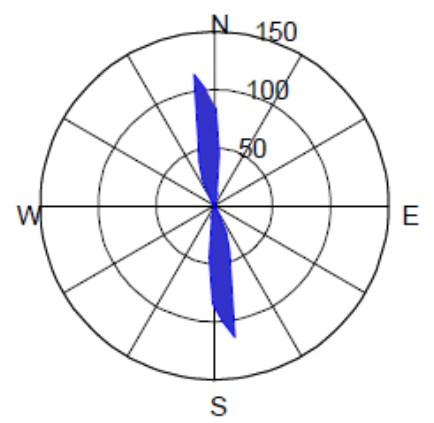

(d)

Fig. 2. An overview of drilling induced wellbore breakouts inferred from an examination of the FMS image data collected in the well WR.

Having the required parameters in place, attempts were made to estimate the in-situ stress [16]. Out of three principal stresses, the vertical stress can be estimated from the integration of density logs which has a gradient of approximately $2.27 \mathrm{SG}$ in different formation. The magnitude of horizontal stresses was estimated using the poroelastic horizontal strain model developed by [9], [17] which were calibrated by extended leak-off (XLOT) test data. The results were then revealed that the strike slip is the dominant stress regime in the studied field. To ensure the accuracy of stress estimation and the geomechanical model a comparison was made between the wellbore failure captured by the caliper log and the one predicted by the geomechanical model using Mohr-Coulomb Failure criteria. It was then found that there is a good consistency between the predicted wellbore failure and the ones observed in Caliper and FMS logs.

The geomechanical model developed can also be used to characterize the fluid flow properties of natural fractures [17], [18]. To do this, the geomechanical model was combined with details of natural fractures captured by the image log in well WR. A Coulomb failure analysis was used to determine the shear and normal stresses acting on the natural fractures planes. The Coulomb failure analysis gives the slip potential of each natural fracture in terms of the Coulomb Failure Function (CFF), but the critical pore pressure is required to cause the fault to slippage. If slip (reactivation) occurs, the sealing material within the fracture breaks and permeability increases. Thus, fracture permeability of the sandstone reservoir can be evaluated by quantifying the mechanical state of these natural fractures and faults [17]. Mohr circles can also be used to identify the drilling trajectory needed to maximize productivity by intersecting the majority of permeable or critically stress natural fractures [19]. The Coulomb frictional failure is defined using (3):

$$
\tau=\mu \sigma_{n}
$$

where $\tau$ is the shear stress, $\sigma_{n}$ is the effective normal stress (i.e., $\sigma_{n}=S_{n}-P_{P}$, where $S_{n}$ is the normal stress and $P_{p}$ is the pore pressure), and $\mu$ is the coefficient of sliding friction [20]. $\tau$ and $\sigma_{n}$ can be calculated based on the magnitude of principal stresses obtained from the geomechanical modeling. The Coulomb failure function states that natural fractures are critically stressed (i.e., expected to slip) when the CFF is positive, as expressed in the (4):

$$
C F F=\tau-\mu\left(S_{n}-P_{P}\right) \geq
$$

Having determined the parameters required, CFF was calculated for the natural fractures using a coefficient of sliding friction of 0.6 , which is a very conservative value [4]. Fig. 3 shows the natural fractures orientation and aperture observed and captured in well WR. Fig. 4 gives a statistical overview of these natural fractures through a series of stereonet plots. The Fig. 4 (a) illustrates the fracture strike while Fig. 4 (b) in the centre describes the natural fractures in terms of fracture strike and fracture dip. The Fig. 4 (c) is also a statistical Kamb contour representation of the fracture orientations [21]. Fig. 5 provides the results of CFF analysis on the natural fractures and the likelihood of their slippage in well WR.

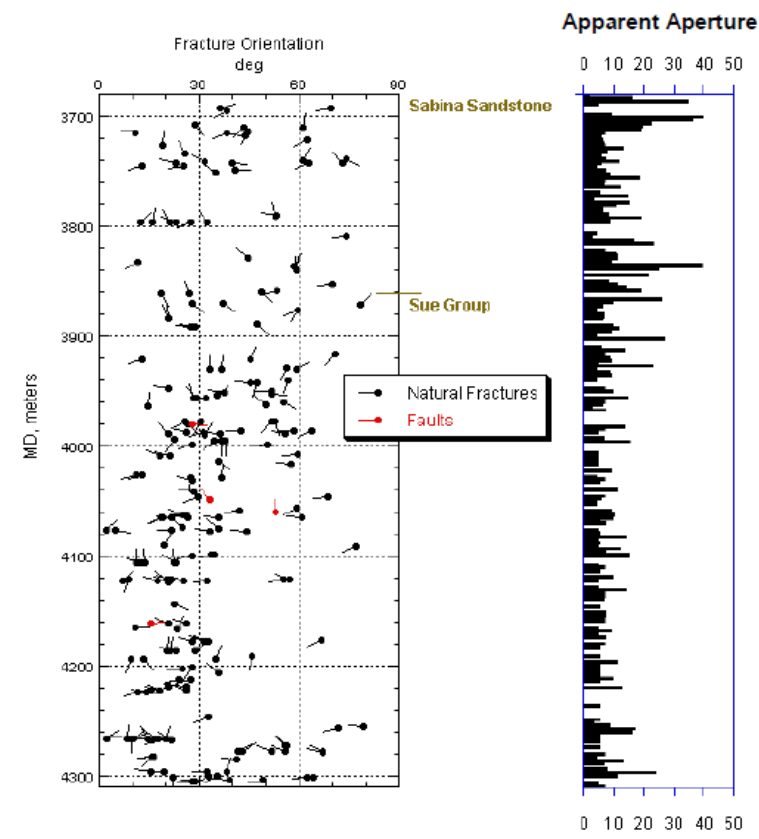

Fig. 3. Natural fractures captured in the FMI image of well WR.

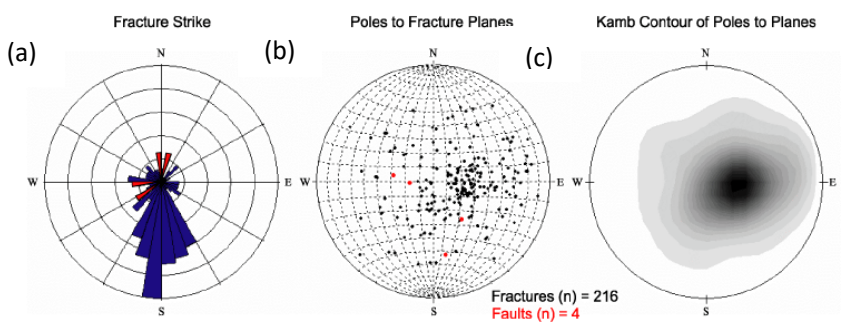

Fig. 4. Statistics of natural fractures observed in the FMI image of well WR. Plot on the left is a rose diagram showing the strike of fractures. The center plot shows the poles to the individual fractures. The plot on the right is a Kamb contour plot of the fracture poles. 
As it is seen in Fig. 5, fractures for which the ratio of shear to effective normal stress fullfills the fault slippage scenario are highlighted in red in the tadpole plot and the 3D Mohr diagram. In the stereographic projection, warm colors are closer to failure than cool colors, based on the value of the stress ratio. Interestingly, majority of natural fractures have a dip of less than $30^{\circ}$ to the west (Fig. 5 (a)), but they are not critically stressed, nor are they at the threshold of being critically stressed in the present day stress field.

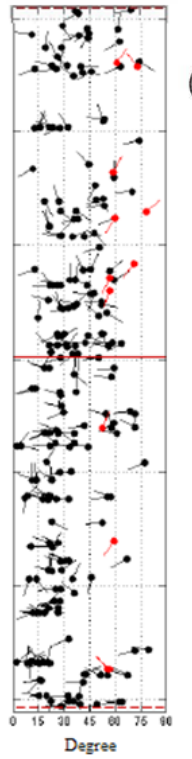

(a)
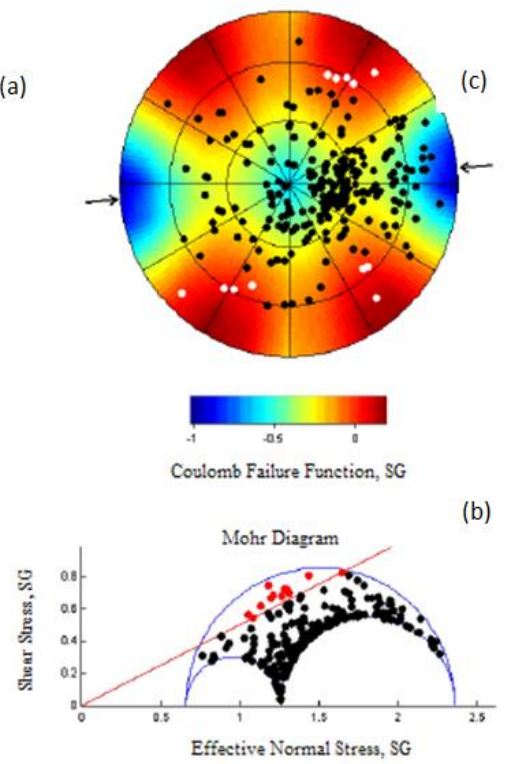

Fig. 5. CFF analysis indicating the likelihood of slippage for natural fractures observed in well WR.

Regardless of fractures ages, the in-situ stress condition determined by the geomechanical model dictates which set of natural fractures is most likely to experience slippage in its current state. If slippage occurs, there is a good chance for fracture permeability to be preserved [22]. The natural fractures that are either critically stressed, or at the threshold of being critically stressed, are indicated by the red tadpoles in Fig. 5 (a), red poles in Fig. 5 (b) and white dots in Fig. 5 (c). Considering the fact that strike-slip stress faulting regime (Shmin $<\mathrm{Sv}<\mathrm{SHmax}$ ) is dominant in the field, the high-angle natural fractures with dips of greater than $60^{\circ}$ in the SW, SE, and NE directions are most likely to be critically stressed and possibly permeable for fluid flow.

Knowledge of natural fractures and their behaviour under the stress state, would also help to have a better field's development and well design. Specifically, a well trajectory can be designed such that it can intersect the majority of critically stressed natural fractures for having a better production from tight formations. However, caution must be taken to interest the critically stresses fractures. For instance, drilling a vertical well would more likely intersect a large population of fractures but if the fractures are not critically stressed, they will not contribute into the production at later stages.

\section{DRILLING IMPLICATIONS}

High deviatoric stresses conducive to active faulting and compressional tectonics may cause the drilling of certain trajectories to be a challenging experience. For instance, some well trajectories may encounter severe wellbore instabilities especially during underbalanced drilling conditions. Herein, it was explored whether underbalanced drilling (UBD) operations within the reservoir are suitable in the context of rock strength and stress conditions. One target of this analysis has been to provide new information specific to the studied field in order to investigate UBD options, or at least, explore well trajectories that could be drilled while maintaining wellbore stability and minimizing formation damage [14].

Here, the built geomechanical model was used to predict the success of UBD drilling sidetracks in the studied reservoir given the uncertainties in the data that built the model. The optimal mud weight required to drill a well successfully depends on the degree of controlled wellbore breakout development design. In some situations, limiting wellbore breakout development is operationally easier than designing a mud program that prevents breakouts from ever forming. This is because excessively high mud weights might not be permissible due to fluid losses through either natural fractures or hydraulic fracturing [10], [14]-[23].

The criteria that was recommend for designing a mud program geomechanical Analysis for the studied field are based on confining breakouts to a maximum of $90^{\circ}$ wide in the vertical sections. If breakouts become wider than $90^{\circ}$, there may be insufficient arch support to prevent hole collapse and catastrophic failure. As hole deviation increases, the maximum limit of breakout development should decrease because the extra cuttings could exacerbate hole-cleaning inefficiencies commonly associated with deviated wells. In this study, a critical breakout width of $30^{\circ}$ was selected for horizontal wells and allow this limit to vary linearly between vertical and horizontal wells based on these $90^{\circ}$ and $30^{\circ}$ limits, respectively. Fig. 6 illustrate how predicted minimum required mud weight varies as a function of well trajectory at a depth of about 3,750 m TVD, which is comparable to the reservoir depths seen in the studied field. In order to recognize the uncertainties in SHmax stress magnitudes, the minimum required mud weight was predicted using SHmax stress magnitudes of 2.8, 3.0, and 3.2 SG. The diagram on the left in Fig. 6 corresponds to the case where SHmax is $2.8 \mathrm{SG}$, while the center diagram corresponds to the case where SHmax is 3.0 $\mathrm{SG}$, and the far right diagram corresponds to the case where SHmax is 3.2 SG. The Sv, Shmin, Pp and Co (UCS) values are constant in all the plots. The two arrows correspond to the SHmax stress direction, which is about $85^{\circ} \mathrm{N}$. Vertical wells would correspond to a point in the center of the plots, while deviated wells would locate outward from the center depending on the hole deviation. For instance, a hole drilled with a deviation of $30^{\circ}$ due north would plot on the first concentric circle at a point closest to the top of the plot (i.e., due North). A horizontal well would plot on the perimeter of the projection depending on the direction of the well. The modeling results for the case where SHmax is about 2.8 SG, indicate that wells drilled in nearly any direction could be drilled underbalanced. However, if the SHmax stress magnitude is about 3.2 SG, UBD applications would be restricted to near vertical wells and highly deviated wells 
drilled in a easterly or westerly direction. Combining information about which natural fractures might be critically stressed, with information on the feasibility of underbalanced drilling along a specific trajectory that intersects these fractures, it becomes clear that underbalanced drilling is possible for most trajectories providing the SHmax stresses less than 3.0 SG. If SHmax is near 3.2 SG, high angle trajectories in the SSW, SSE, NNW or NNE directions could be drilled underbalanced; however, these trajectories would encounter a greater degree of rock failure. This is not to suggest that the well cannot be drilled UBD, but extra attention to hole cleaning practices may be required.
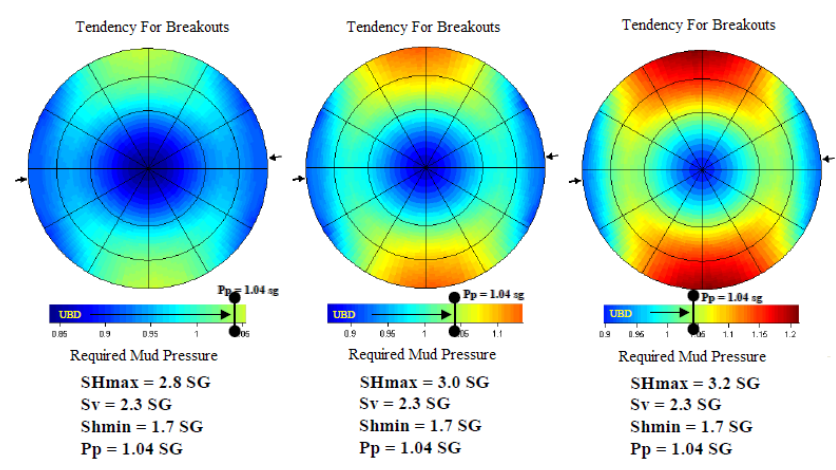

Fig. 6. Lower hemisphere stereographic projections showing required mud weight to prevent hole collapse calculated at 3,750 m TVD in the studied field. The color scale is the same for all plots (i.e., 1.07 SG is yellow). The small vertical black line on the scale corresponds to the reservoir pore pressure in the studied field. Contours shown in all plots correspond to mud weight or collapse pressure recommended to control wellbore breakout development. Depending on the SHmax stress magnitude, there are trajectories that can be drilled underbalanced for the specified breakout allowance.

\section{HYDRAULIC FRACTURING IMPLICATIONS}

An alternative approach to use the critically stressed or near critically stressed natural fractures is to use them to have better hydraulic fractures propagating deep into formations. It should be noticed that hydraulic fracture will propagate in the direction of maximum horizontal stress once the fracture propagates far from the borehole. Technically speaking, it seems probable that hydraulic fractures obliquely intersect with these natural fractures, creating a good production scenario. However, few important issues should be considered in order to effectively connect hydraulic to natural fracture. One special issue might be pumping hydraulic fluids. For a vertical well or deviated wells with an inclination of 30 degrees, creating and linking tensile fractures and propagating these fractures will not require excessive pressures $(<2.0 \mathrm{SG})$. However, a highly deviated well drilled towards north, south NE, NW, $\mathrm{SW}$, or SE, may require excessive pressures to efficiently create, link, and propagate fracture away from the borehole. Fig. 7 shows the pressure needed to induce a tensile fracture in different directions.

Another important thing to consider is that fact that if the fracture propagates away from the borehole and intersects several critically stressed fractures, it would be necessary to use suitable proppant to keep the induced fracture opened. In fact, the proppant must be able to sustain the stress applied by Shmin, which is acting perpendicular to the hydraulic fracture.
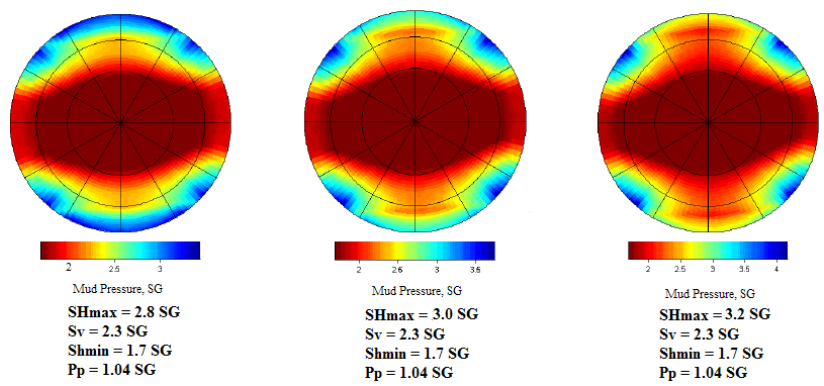

Fig. 7. Pressure requires to induce a tensile fracture in different directions at $3,750 \mathrm{~m}$ in the studied field.

\section{CONCLUSION}

The comprehensive fracture and geomechanical analysis carried out in this study indicated that:

1) The geomechanical model built for the studied filed indicated that the strike-slip is dominant faulting regime. The direction of maximum principal horizontal stress (SHmax) appears to be $\mathrm{N} 80^{\circ} \mathrm{E} \pm 2^{\circ}$ which was consistent with the breakouts observed in image log of well WR.

2) A High angle sidetrack with the inclination of greater than $60^{\circ}$ from the existing well drilled towards north or south would be the optimum directions for intersecting natural fractures that are either critically stressed or at the threshold of being critically stressed. Although other trajectories might intersect a greater population of natural fractures, they may not be critically stressed to provide a good fluid flow.

3) Wellbores with trajectories that intersected these critically stressed natural fractures could be drilled with a low mud weight to minimize formation damage. There is some uncertainty in the maximum horizontal stress magnitude that would imply that some trajectories could be drilled underbalanced.

4) It seems that if a hydraulic fracturing operation is implemented in the studied field, induced fractures would intersect natural fractures that are either critically stressed or at the threshold of being critically stressed. However, wellbore trajectory design would be crucial to intersect most of the critical fractures. For a vertical well or wells drilled with an inclination of 30 degree, inducing and linking tensile fractures with natural fractures would not require excessive pressures $(<2.0$ $\mathrm{SG})$. However, for wells with a higher inclination angle wells deviated towards north, south NE, NW, SW, or $\mathrm{SE}$, excessive pressures might be required to efficiently create, link, and propagate induced fracture away from the borehole.

\section{REFERENCES}

[1] S. A. Holditch, "Tight gas sands," Journal of Petroleum Technology, vol. 58 , no. 6 , pp. 86-93, 2006.

[2] S. Khatibi, M. Ostadhassan, D. Tuschel, T. Gentzis, B. Bubach, and H. Carvajal-Ortiz, "Raman spectroscopy to study thermal maturity and elastic modulus of kerogen," International Journal of Coal Geology, vol. 185, pp. 103-118, 2018.

[3] S. E. Laubach, J. E. Olson, and J. F. Gale, "Are open fractures necessarily aligned with maximum horizontal stress?" Earth and Planetary Science Letters, vol. 222, no. 1, 2004. 
[4] J. Byerlee, "Friction of rocks," Pure and Applied Geophysics, vol. 116, no. 4, pp. 615-626, 1978.

[5] T. Finkbeiner, C. A. Barton, and M. D. Zoback, "Relationships among in-situ stress, fractures and faults, and fluid flow: Monterey Formation, Santa Maria Basin, California," AAPG Bulletin, vol. 81, no. 12 , pp. 1975-1999, 1997.

[6] M. D. Zoback and J. H. Healy, "In situ stress measurements to $3.5 \mathrm{~km}$ depth in the Cajon Pass scientific research borehole: Implications for the mechanics of crustal faulting," Journal of Geophysical Research: Solid Earth, vol. 97, no. B4, pp. 5039-5057, 1992.

[7] M. D. Zoback, D. Moos, L. Mastin, and R. N. Anderson, "Well bore breakouts and in situ stress," Journal of Geophysical Research: Solid Earth, vol. 90, no. B7, pp. 5523-5530, 1985.

[8] M. Tingay, J. Reinecker, and B. Müller, "Borehole breakout and drilling-induced fracture analysis from image logs," World Stress Map Project, pp. 1-8, 2008.

[9] S. Khatibi, A. Aghajanpour, M. Ostadhassan, and O. Farzay, "Evaluating single-parameter parabolic failure criterion in wellbore stability analysis," Journal of Natural Gas Science and Engineering, vol. 50, pp. 166-180, 2018.

[10] S. Khatibi, A. Aghajanpour, M. Ostadhassan, E. Ghanbari, E. Amirian, and R. A. Mohammad, "Evaluating the impact of mechanical properties of kerogen on hydraulic fracturing of organic rich formations," in Proc. SPE Canada Unconventional Resources Conference, Calgary, Alberta, Canada, March 13-14, 2018.

[11] F. Khoshbakht, H. Memarian, and M. Mohammadnia, "Comparison of Asmari, Pabdeh and Gurpi formation's fractures, derived from image log," Journal of Petroleum Science and Engineering, vol. 67, no. $1,2009$.

[12] A. Alexeyev, M. Ostadhassan, R. A. Mohammed, B. Bubach, S. Khatibi, C. Li, and L. Kong, "Well log based geomechanical and petrophysical analysis of the bakken formation," presented at 51st U. S. Rock Mechanics/Geomechanics Symposium, San Francisco, California, USA, June 25-28, 2017.

[13] D. Moos and M. D. Zoback, "Utilization of observations of well bore failure to constrain the orientation and magnitude of crustal stresses: Application to continental, deep sea drilling project, and ocean drilling program boreholes," Journal of Geophysical Research: Solid Earth, vol. 95, no. B6, pp. 9305-9325, 1990.

[14] A. Aghajanpour, S. H. Fallahzadeh, S. Khatibi, M. M. Hossain, and A. Kadkhodaie, "Full waveform acoustic data as an aid in reducing uncertainty of mud window design in the absence of leak-off test," Journal of Natural Gas Science and Engineering, vol. 45, pp. 786796, 2017.

[15] B. A. Eaton, "The equation for geopressure prediction from well logs," presented at Fall Meeting of the Society of Petroleum Engineers of AIME, Dallas, Texas, USA, Sep. 28 - Oct 1, 1975.

[16] P. Peška and M. D. Zoback, "Compressive and tensile failure of inclined well bores and determination of in situ stress and rock strength," Journal of Geophysical Research: Solid Earth, vol. 100, no. B7, pp. 12791-12811, 1995.

[17] C. A. Barton, S. Hickman, R. H. Morin, M. D. Zoback, T. Finkbeiner, J. Sass, and D. Benoit, Fracture Permeability And its Relationship to in-Situ Stress in the Dixie Valley, Nevada, Geothermal Reservoir, 1997.
[18] M. Brudy and M. D. Zoback, "Compressive and tensile failure of boreholes arbitrarily-inclined to principal stress axes: application to the KTB boreholes, Germany," International Journal of Rock Mechanics and Mining Sciences \& Geomechanics Abstracts, vol. 30, no. 7, pp. 1035-1038. Pergamon, 1993.

[19] K. Bisdom, G. Bertotti, and H. M. Nick, "A different perspective on critically stressed fractures and their impact on fluid flow," in Proc. AAPG Annual Convention and Exhibition.

[20] J. C. Jaeger, N. G. Cook, and R. Zimmerman, Fundamentals of Rock Mechanics, John Wiley \& Sons, 2009.

[21] W. B. Kamb, "Ice petrofabric observations from Blue Glacier, Washington, in relation to theory and experiment," Journal of Geophysical Research, vol. 64, no. 11, pp. 1891-1909, 1959.

[22] T. Ito and M. D. Zoback, "Fracture permeability and in situ stress to 7 $\mathrm{km}$ depth in the KTB scientific drillhole," Geophysical Research Letters, vol. 27, no. 7, pp. 1045-1048, 2000.

[23] J. H. Norbeck, "Identification and characterization of natural fractures while drilling underbalanced," Ph.D. dissertation, Dept. Petroleum Eng., Colorado School of Mines, Golden, Colorado, 2011.

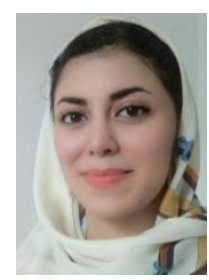

Azadeh Aghajanpour received her bachelor and master degrees from Amirkabir University of Technology in 2012 and 2014, respectively. She is currrently a PhD student at Curtin University Malaysia and working on drilling and Geomechanics.

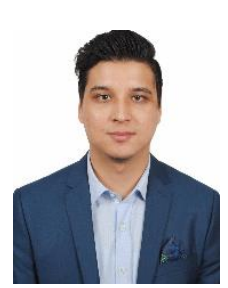

Roohullah Qalandari received his bachelor degree from Curtin University Malaysia in 2017. He is currently working on drilling fluid. He is currently working on application of nanoparticles in drilling fluid

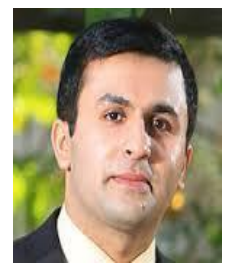

Raoof Gholami received his $\mathrm{PhD}$ degree from Shahroud University in 2016. He is currently a senior lecturer of Petroleum department in Curtin University Malaysia. His specializations are drilling and geomechanics. He also has been involved in various Geomechanical related projects ever since. 